
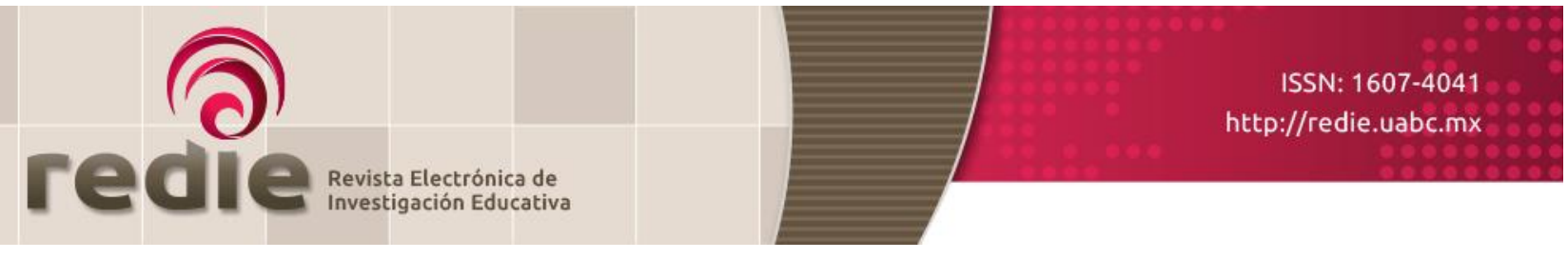

Vol. 19, Núm. 2, 2017

\title{
El saber profesional de una maestra de Infantil ${ }^{1}$ Professional Knowledge of a Pre-School Teacher
}

\author{
Susana Orozco Martínez (*) susanaorozco@ub.edu \\ (*) Universidad de Barcelona \\ (Recibido: 2 de marzo de 2015; Aceptado para su publicación: 18 de noviembre de 2015)
}

Cómo citar: Orozco, S. (2017). El saber profesional de una maestra de infantil. Revista Electrónica de Investigación Educativa, 19(2), 143-157. https://doi.org/10.24320/redie.2017.19.2.1103

\section{Resumen}

El artículo expone los saberes y práctica profesional de María, maestra de Educación Infantil de una escuela pública de Cataluña, a cargo de 24 estudiantes (13 niñas y 11 niños). La recolección de datos posibilita profundizar en sus experiencias pedagógicas y en el proceso educativo que pone en marcha, y que contribuyen en la creación y desarrollo de una relación educativa caracterizada por la atención a las necesidades individuales y a la singularidad de sus alumnos, desde un acompañamiento, acogimiento y cuidado de lo que se vive en el aula.

Palabras clave: Conocimiento, experiencia, práctica educativa, formación docente.

\begin{abstract}
This paper sets out the professional knowledge and practice of María, a pre-school teacher with three years of experience in a public school in Catalonia and 13 girls and 11 boys in her care. The data collected enables further understanding of her teaching experiences and the educational process she uses, which contribute to the creation and development of an educational relationship marked by a focus on individual needs and the unique characteristics of each child, and describes the support and care provided throughout classroom experiences.
\end{abstract}

Keywords: Knowledge, experience, educational practice, teacher training.

\section{Introducción}

Cuando hablamos de saberes pensamos generalmente en el saber vinculado al conocer, al hacer y al ser. Reggio (2010) agrega un cuarto saber, el fundacional, de la vida, aquél dispuesto a generar y sostener a los otros, alimentado de experiencias profundamente vividas que, analizadas y reflexionadas, enriquecen

1 El artículo se desarrolló en el marco de la Investigación: "El saber profesional en docentes de educación primaria y sus implicaciones en la formación inicial del profesorado: estudios de casos" (ref.: EDU2011-29732-C02-01) financiada por el Ministerio de Economía y Competitividad durante el período 2012-2014. 
los contenidos y proposiciones teóricas que se incorporan en las aulas. Cuarto saber que aunque individual, en su andadura se enriquece con los otros; saber y aprendizaje experiencial que "viene de la cotidianidad (material, relacional, social política) que vivimos y encuentra en ella sus propias razones" (Reggio, 2010, p.14).

Durante la práctica profesional, el docente despliega una serie de habilidades que se fueron nutriendo a partir de los conocimientos, la intuición, de las circunstancias vividas y de la capacidad de aprender a partir de ellas (Reggio, 2010). Ese cúmulo de saberes que se aprende y de los que se dispone no puede ser aislado de la experiencia, fundamento de todo aprendizaje (Boud, Cohen y Walker, 2011). Se aprende desde y a partir de nuestras experiencias con independencia de los estímulos externos (libros, materiales, educadores, etc.) que hayamos recibido; experiencias externas que, a su vez, actúan transformando las experiencias previas (Boud et al., 2011).

Boud et al. (2011) señalan que creemos "que reflexionar sobre la experiencia personal es un factor importante para conseguir un buen aprendizaje" (p.15). Considerados así, los saberes y vivencias podrían erigirse en los cimientos de un planteamiento educativo diferente, con nuevas significaciones y alcances. Sin embargo, en muchas ocasiones la experiencia personal intensamente vivida en comunidad es devaluada en pos de la objetividad y la generalidad (Boud et al., 2011). Y en las escuelas esta indiferencia institucional hace que las propuestas pedagógicas con alto contenido significativo experiencial desarrolladas en el seno del aula, no se vean reflejadas del todo en algún documento escrito (Garay, 2000). Y al no registrar esas producciones pedagógicas, los relatos de experiencias innovadoras y los aconteceres cotidianos van perdiéndose en el camino. Así es como las instituciones educativas pierden la posibilidad de conocerlas, compartirlas y transferirlas al seno del centro.

Este artículo analiza la forma en que María despliega su experiencia, e intento teorizar sobre aquellas cualidades y procederes pedagógicos que emplea con sus estudiantes. Procederes que se materializan en la manera en que organiza y selecciona las actividades en el aula y en los planteamientos didácticos que planifica para la adquisición de los aprendizajes, donde las vivencias de los niños forman parte del currículum. La intención de este trabajo no es generalizar sino ubicar la experiencia y el modo en que se desarrolla.

Hablar de experiencia en el ámbito educativo nos conduce hacia nociones que, con más de un significado, ha llevado a diversos autores a profundizar en el tema (Arendt, 1996, 2005; Contreras y Pérez, 2010; Dewey, 1995; Gadamer, 1977; Larrosa, 2009; Reggio, 2010). Vertientes disciplinares como la Filosofía, la Antropología, la Sociología, la Estética, la Política, la Pedagogía y la Psicología han intentando encontrar respuestas a este tema. En general, hay explicaciones y definiciones poco claras; principios y esquematizaciones que marcan el camino sin que haya acuerdos al respecto. A pesar de ello, hay un factor que sí es contemplado por todas las disciplinas: las potencialidades formativas que contiene en sí misma la experiencia (Reggio, 2010).

La dimensión temporal y la imagen de acumulación aparecen casi inevitablemente cuando pensamos en experiencias. Parecería que la cantidad de años avala el poseer más experiencias; sin embargo, la vinculación de veteranía y acopio de vivencias puede encerrar una falacia: "Pensar que vivir situaciones o acontecimientos implica haber logrado experiencia".

Otro componente que se incorpora al análisis hace referencia a la afirmación de que la práctica docente enriquece las habilidades y experiencias pedagógicas. Aseveración que puede llevarnos a confundir el tema, ya que estar a cargo de un grupo, aunque contribuye en el logro de experiencias profesionales, por sí mismo no avala el tener experiencias altamente significativas. Las experiencias serán representativas en la medida en que se desarrolle una disposición personal para acoger lo singular de los acontecimientos y proveerlos de nuevos significados. Por ello es que cuando hablemos de experiencia educativa se hará referencia a aquellas que se transforman en saberes, que se pueda aprender algo de ellas, que hagan pensar y reflexionar (Contreras y Pérez, 2010). Si así no fuera se estaría antes vivencias que pasan, pero que no dejan huella (Larrosa, 2009). 
La conexión entre experiencia y pensamiento hace que ambas se necesiten. "Decía Hannah Arendt que no es posible pensar sin experiencia personal" (Contreras y Pérez, 2010, p. 21). Son las circunstancias y los acontecimientos que vivimos los que vehiculizan un proceso de pensamiento que se puede traducir en experiencias cuando "algo" nos ocurrió y es ineludible repensarlo. Vivencias que en ahora adquieren significado distinto al ubicarlas en nuevos contextos.

Como profesor, una de las fuentes de intuiciones más útiles y más ignoradas en relación con el propio ejercicio profesional es la autobiografía de uno mismo como aprendiz. Tal vez sea por el carácter emocional de las experiencias que representa la propia autobiografía. (Boud et al., 2011, p. 33).

De allí es que volver a nosotros mismos, reconocer los trayectos biográficos-educativos, puede llevarnos a ubicar a las experiencias en el lugar de los saberes y no como meras anécdotas de nuestras vidas. En la experiencia personal no podemos reconocer solo aquella que es palpable, visible, tangible. Existen también las experiencias internas, inapreciables a veces, pero que en sí mismas se constituyen en válidas y ricas para nuestras vidas. Vivencias personales, perceptibles o no a primera vista que traspasan al ámbito profesional aportando a la práctica pedagógica nuevas perspectivas. Interrogarlas y dejarlas hablar es lo que se pretende en este artículo, dándole entidad propia a la experiencia de María que desde el análisis y reflexión puede ayudarnos a repensar nuestra práctica pedagógica.

\section{Metodología}

El abordaje del tema requiere una perspectiva metodológica multidimensional, con la utilización de diversos enfoques y herramientas de indagación. Se recurrió a la perspectiva cualitativa-interpretativa en educación, con los aportes de la etnografía, la investigación biográfico-narrativa y la fenomenología hermenéutica. El proceso de investigación se realizó a lo largo del curso escolar 2012-2013, mediante una observación participante por semana.

Investigar desde una perspectiva multidimensional requiere ubicar los instrumentos de indagación cualitativa en distintos espacios, tiempos y dimensiones, con niveles de amplitud y profundidad en el análisis que posibilite comprender lo que allí está pasando. Dimensiones tales como lo personal y profesional, lo privado y público, lo individual y social, lo vincular y relacional, permiten preguntarse cómo vive y cómo se vive María en la escuela, en el aula, en la hora del patio, con sus pares, las familias y los estudiantes; en definitiva, María en relación con ella misma y con su entorno.

Concuerdo con van Manen (2003, p. 20) cuando se pregunta: "¿Por qué es necesario adoptar una determinada aproximación a la investigación y no otra? Investigar y hacerlo de cierta manera responde a un posicionamiento y una concepción de la vida particular. No es posible abstraerse de ello ante la realidad, de allí es que a lo largo del proceso investigativo no busqué en María a una informante, a alguien que proporcionara datos, sino a una persona con quien compartir y construir saberes y aprendizajes mutuos.

Para construir conocimientos es necesario introducirse en procesos indagatorios distintos y complementarios entre sí. Preguntar, no aceptar fácilmente las respuestas que desde diversas fuentes llegan; tener un grado de imaginación (relaciones, supuestos, hipótesis, etc.) para sostener los hechos e informaciones que se tiene e interpelarlos; volver a ellos, volver a las preguntas sencillas: ¿qué está pasando?, ¿por qué está pasando?, ¿qué sabemos?, ¿cómo avanzamos?, ¿cómo revisar las situaciones que se presentan?

Muchos de los estudios actuales se inclinan a la investigación reflexiva, dado que abordan el conocimiento a partir de la experiencia, de la textualidad del significado y del valor de la singularidad de las vivencias personales (van Manen, 2003), que al ser compartidas llevan a la introspección a quienes se encuentran en iguales o similares situaciones. Lo importante es que desde la mirada fenomenológica hermenéutica no se aporta "un sistema basado en procedimientos, sino que, más bien, su método requiere y exige la capacidad de ser reflexivo, intuitivo, sensible al lenguaje y constantemente abierto a la 
experiencia" (van Manen, 2003, pp.10-11). Es por ello que de las informaciones recibidas a lo largo de las observaciones, conversaciones, visitas al teatro y a la granja con los estudiantes, dirigía mi atención hacia distintos momentos; no me limitaba a los "lugares" comunes -aquellos en los que suceden los acontecimientos-, ni a las personas "autorizadas" a darme información. Era necesario ir más allá, descubriendo en los sujetos, en las prácticas, en los espacios, en la vida institucional, en los silencios, los indicios o marcas que daban significado y que explicaban lo que allí ocurría. Los "objetos inanimados" (Eisner, 1998) a veces ignorados, dan cuenta también de lo que en un espacio concreto (aula, patio, sala de maestras) ocurre y se desarrolla; señalan relaciones, jerarquizan situaciones, privilegian ideologías. Esto no puede ser dejado de lado.

Entrar a una escuela, a un aula, requiere entonces explorar lo que encierra la misma, desentrañar el modo en que se tejen los componentes universales y particulares en esa institución, en esa aula y en esa docente singular (Garay, 1997).

Este es un camino constante de idas y vueltas, acercamientos y retrocesos, avances y esperas, que requiere de quien investiga mucha paciencia, porque cuando creemos que lo que escuchamos $u$ observamos es representativo de algo o nos informa acerca de alguna cosa o persona, un nuevo acontecer puede cuestionar lo hasta ahí afirmado.

A pesar de que mi posicionamiento metodológico era claro, advertía que en la vasta bibliografía consultada, en las técnicas o herramientas propuestas para la indagación, lo que primaba era un enfoque rígido y estandarizado de lo que se debía hacer y cómo debía hacerse. Quedaba poco margen para la intuición, "la fina observación, la escucha atenta, la implicancia en la relación con quienes o aquello que se busca conocer y comprender, condiciones propias de una investigación humana como es la educativa" (Arévalo, 2007, p. 4). Comprendí que los instrumentos de investigación son sólo herramientas que nos ayudan a aprehender la realidad que deseamos indagar, pero son las circunstancias -una reflexión de María, los imponderables de la vida y de las relaciones- los que van señalando el camino de la investigación. Si el proceso investigativo se lo plantea desde la rigidez de la herramienta, podríamos dejar de ver, quizá, lo que realmente sucede en esa aula, con esa maestra y con sus niños. No obstante, no podemos desdeñar los caminos metodológicos, ya que contribuyen y guían el proceso por sendas con sentido y significados pertinentes.

\section{Hallazgos}

\subsection{Encuentro investigativo a partir de la relación}

Con María habíamos compartido momentos de intercambio pedagógico y conocía su compromiso y sensibilidad con la tarea docente. Siempre le adjudiqué autoridad, aquella que se otorga a alguien por su saber ser y estar en el mundo, por su posicionamiento ante la vida y, fundamentalmente, por la manera en cómo vive e interpreta el encuentro educativo. Autoridad que señala Pérez (1997), como se cita en Arnaus (1998, p. 36):

Se trata de una autoridad que sólo nos es dada cuando nos convertimos en sujetos protagonistas de nuestra acción educativa, que consiste en despertar la capacidad de ser sujetos en nuestro alumnado. Es una autoridad basada en el "ser" autoras y autores de nuestras prácticas en las instituciones educativas y no en "tener" una función reproductora de prácticas dadas por otras instancias educativas.

Garay (1997) señala que el modo y la forma en que la negociación y entrada al campo se efectúe conlleva "diferentes efectos sobre el establecimiento del vínculo", de ahí la importancia de diseñar la manera en que nos acercaremos. El primer diálogo con fines investigativos se transformó en un reencuentro en el que, como si de una trama dialógica y polifónica se tratara, fuimos entretejiendo nuestras vivencias y relatos. Encuentro abierto, colmado de recuerdos reconstruidos desde las historias que queríamos contar. 
El proceso de investigación contempló la permanencia en el campo durante un curso escolar, la observación participante -una vez a la semana, cada martes, y entrevistas-conversaciones a lo largo de todo proceso. La indagación estuvo siempre apoyada en el diario de campo, instrumento imprescindible en el que registraba no sólo lo que iba sucediendo, si no lo que como investigadora me iba sucediendo mientras estaba con María. No obstante, ir al campo no implica sólo desplazarse hacia el lugar donde se realizará la investigación; ir involucra "estar" en él, pero de una manera determinada, donde la condición de investigadora no se asocie a la de una posición superior y distante (Velasco et al., 2007), y donde es necesario aplicar el sentido común y los principios científicos, evitando recurrir a un atajo que nos lleve directamente hacia lo que deseamos que ocurra (Malinowski, 2007). Bateson (2004, p. 199) señala que "uno busca la regularidad de la conducta, pero, siendo un forastero, desconoce las normas y expectativas que utilizan los demás como marco de comprensión mutua y previsibilidad", ya que cada contexto es único e irrepetible, por ello es que posicionarme como una principiante sin experiencia ayuda a descubrir, describir, comprender y analizar lo que en esa situación y con esas personas está ocurriendo.

En el proceso de investigación desarrollado convivieron la observación participante con la entrevistaconversación (Guber, 2012; Hammersley, Atkinson, 1994; Velasco et al., 2007) sobre los sucesos del aula y los saberes que ponía en juego María desde su experiencia docente. Entrevista-conversación interpretada como sinónimo de diálogo, interacción e interrelación que se produce entre dos o más personas, en la que ambas contribuyen a y en la construcción de un texto, de una narración. Lo que pretendía a través de la conversación era que mis reuniones con María no estuvieran mediatizadas por un "artefacto técnico" (Guber, 2012) sino por un encuentro que posibilitara que el tejido cotidiano que va elaborando junto a sus niños tomara forma, se revelara.

La observación directa es un dispositivo que permite observar metódica y sistemáticamente los distintos momentos de la vida educativa, social y cultural de un grupo; y permite participar y actuar como lo hacen los distintos miembros de una comunidad (Guber, 2012). Ello posibilitó que los "imponderables de la vida real y el comportamiento diario" (Malinowski, 2007) salieran a la luz y explicaran lo que estaba pasando. Vida que se desarrollaba en diferentes escenarios y tal y como se presentaban con los niños: en el quehacer diario del aula, en salidas programadas, en horas del patio y en las reflexiones que la maestra y yo hacíamos en voz alta sobre sus pensamientos, preocupaciones e inquietudes.

Compartir la investigación con María desde una perspectiva multidimensional-cualitativa facilitó indagar en su experiencia, recapacitar y designarla, descubriendo el sentido, significado y valor que tienen las vivencias personales, así como los modos y procederes pedagógicos que orientan su práctica docente.

Así fue como, desde la negociación de mi ingreso al aula, pasando por la permanencia de un año escolar en la escuela, hasta la despedida-cierre de la investigación, el trayecto compartido posibilitó -tanto a la maestra como a mí- vivir un proceso de transformación personal y profesional. Las vivencias se conviertieron en experiencias.

\subsection{El planteamiento pedagógico en el aula}

María pone en marcha una manera de llevar a cabo el proceso educativo a la que denomino "cualidades o procederes pedagógicos", aquellos fundamentos o principios que orientan, dirigen y ayudan al profesorado en la preparación, planificación y desarrollo de su intervención educativa. Cualidades y maneras de estar e interpretar la educación que cada docente despliega y hace de una forma determinada. Van Manen (1998) señala que el "tacto consiste en una serie compleja de cualidades, habilidades y competencias". Una persona que tiene tacto pedagógico es aquella que tiene la habilidad de saber interpretar los pensamientos, sentimientos y deseos interiores a través de los gestos, comportamiento, expresión y lenguaje corporal que expresa el otro. "El tacto consiste en la habilidad de interpretar la importancia psicológica y social de las características de esta vida interior". No obstante esta receptividad, una persona con tacto posee un claro significado de las normas, límites y equilibrio, lo que la lleva a saber qué es lo que hay que hacer en una situación concreta, gracias a la intuición moral que posee. (Van Manen, 1998, p. 137). 
Reconocí en María ese tacto pedagógico cuando la vi actuar con sus estudiantes en la escuela, desarrollando su tarea con sensibilidad, seguridad, con confianza en ella misma y en los niños, a pesar de lo delicadas o complejas que fueran las circunstancias que vivía. Durante el tiempo que permanecí en la escuela me costaba descubrir, dentro de la circularidad de las actividades, aquellas pistas, cualidades, signos o manifestaciones que me permitieran interpretar lo que estaba pasando. A veces la previsibilidad y la ejecución de ciertas acciones en las escuelas son tan claras que nos cegamos o perdemos (Suárez, 2011), dejamos de mirar. A pesar de ello, lo inesperado aparece, se manifiesta y no es posible predecir. Malinowski (2007) nombra como incidentes claves aquellas situaciones, acciones o momentos que abren la posibilidad al análisis. Y es allí, justamente en la sorpresa, en lo accidental y aleatorio donde aparece, "ese" saber que se estaba buscando.

Es mayo. Salimos al patio a ver el tiempo. El día está hermoso: sol, cielo celeste limpio, aire puro. A los niños y niñas los veo contentos, van sujetados de las batas y pasan junto a la jardinera, donde intentan acariciar a las plantas que hay en las mismas. ¡No puedo creer! ¡Las plantas! La única jardinera que tiene las plantas vivas y bonitas son las de María, el resto están muertas, no hay o están en mal estado. Le hago referencia a María sobre lo que acabo de ver y me dice: "Las otras maestras 'se quejan' porque mis plantas son las únicas que sobrevivieron al invierno. Bueno, nosotros las cuidamos todo el año." (Extracto del diario de campo).

La vida se hace presente en el aula. Cuidar las plantas forma parte del hacer cotidiano de esta maestra y de otras que colocan en el centro del encuentro educativo al cuidado de la relación con sus alumnos. Este hecho puntual desveló las cualidades y procederes pedagógicos que María puso en juego durante todo el año: acoger, acompañar y cuidar, desde los niños, familias, compañeras de escuela, hasta las plantas que embellecen el lugar que les pertenece.

\section{3 ¿Qué enseñamos en la Universidad?}

Conviviendo con María y los niños pude descubrir el entramado que se desarrolla en casi todas las aulas. El tiempo compartido, junto a las conversaciones llenas de sentidos y representaciones, desvelaban los sentimientos y dificultades con las que se encontró y encuentra en el camino de la enseñanza. Historias escolares y personales que se entrelazaban a partir de sus reflexiones como mujer, docente, madre, hija y pareja. Todas y cada una hacían que se ubicara en distintos lugares y se entremezclara con las expectativas que tiene, en las impresiones sobre el papel de la escuela, el lugar de los maestros actuales, los "requisitos" рага ser buena docente y los supuestos y comprensiones pedagógicas que subyacen en toda acción educativa.

Pensar en voz alta me permitía, como docente e investigadora, preguntarme una y otra vez (junto a María) sobre lo concreto y lo no tan evidente que sucedía en el aula, que no tiene una traducción teórica y, por ende, no forma parte de la formación universitaria.

Acaba la hora del patio y entra al aula Arnau con los pantalones mojados. María se acerca y advierte que el niño se orinó. Va a un armario, extrae una bolsa con ropa de recambio, llama a Arnau y se dirigen al lavabo, donde lo lava y cambia. Me mira y me dice: "A que esto no les enseñas a tus estudiantes en la Universidad?, ¿sabrán que tendrán que hacerlo?" (Extracto del diario de campo).

Estos haceres desarrollados con naturalidad, a los que cuesta "teorizar" y ponerles palabras "técnicas"; pocos o directamente no referenciados por autores y difíciles de encontrar en la bibliografía, son los que en la cotidianidad del aula viven las maestras de infantil. Saberes prácticos que reclaman los estudiantes universitarios que les enseñemos, pero que en general no tienen cabida en los espacios universitarios. ¿Cómo hacer entonces que lo que sucede en las escuelas llegue a la universidad? Recurrir a esta experiencia, no como una anécdota sino como una realidad que existe y merece ser analizada, se constituye en una estrategia de aproximación y reflexión al interior de una realidad escolar que, con esta maestra y seguramente con muchas más, sí existe. Una maestra que vive y se vive en el aula desde la naturalidad de la situación y que responde como, quizás, toda persona lo hubiera hecho: limpiar al niño 
que está mojado.

María sigue limpiando a Arnau y continúa hablando: "Porque cuando yo estudiaba para maestra no había asignatura ni profesor que te dijera que en las aulas de infantil te encontrarías con esto, sólo estaban preocupados en que supiéramos qué íbamos a enseñar, cómo y por qué... y de lo cotidiano, ¿qué?, pues nada." (Extracto del diario de campo).

¿Qué relación se da entre ese contexto concreto del aula y el teórico que supuestamente se desarrolla en la Universidad?, Freire (2008b, p. 124) señala:

El mundo fue dejando de ser para nosotros el simple soporte sobre el que estábamos, y por el otro se transformó o se ha venido transformando en el mundo con el cual estamos en relación [...]. De este modo, la vida se ha ido transformando en una acción en el mundo, desarrollada por sujetos que poco a poco han ido ganando conciencia de su propio hacer sobre el mundo.

¿Qué hay de implícito de la teoría aprendida durante su formación inicial y permanente y la práctica, saber de la experiencia que desarrolla María? En la Universidad, ¿qué enseñamos?, ¿cuidamos y acogemos la vida y la cotidianidad que se desarrolla en el aula?

\subsection{Acompañar y cuidar cuando se requiere}

María acoge, acompaña y cuida porque reconoce la vida que le rodea. Acompañar, desde la óptica de Bruyelles (1996), como se cita en Comas y Funes (2001), es aceptar y dejarse interpelar por el otro, ayudándolo durante su trayecto para que sea él y no nosotros quien encuentre su camino y proyecto, respetándolo por lo que es, por sí mismo.

Escuchar y dar lugar a las historias que cada criatura tiene supone reconocer y acoger la singularidad en el aula, conocer y comprender los contextos y circunstancias que rodean la vida de cada infante dando respuestas coherentes a las necesidades que este niño en particular hoy tiene.

Estamos en el patio y María comenta: “Sabes lo que me pasó con Nuria? Yo observaba que no quería caminar, solo sentarse. En un primer momento no comprendía el porqué, hasta que al verla caminar casi me muero, ¡los zapatos!, iqué pequeños eran! Decidí que lo mejor sería que estuviera descalza dentro de la clase. ¿No vas a creer?, -continúa-, para algunas maestras que la niña estuviera descalza en la clase no les parecía bien. ¿Te das cuenta?, ¿qué es lo importante, la comodidad de Nuria o que sufra todo día porque no se puede ni mover? ¡Yo no las entiendo a veces! ¿Por qué cuesta ubicarnos en el lugar de los otros, qué más da si va descalza o con zapatos? ¿Qué!, ¿acaso aprenderá menos?" (Extracto del diario de campo).

Van Manen (1998) dice que "el tacto pedagógico es un caso especial del tacto social general". Ponerse en el lugar de la otra es comprender lo que a la niña le puede estar pasando, reconocer los signos que el cuerpo envía y advertir que los zapatos, quizás, están informando de otras circunstancias que pueden estar afectando a la niña y que María, como maestra, no puede cambiar pero sí minimizar. Por eso su decisión va más allá de un gesto o atención especial, denota el tacto, la vinculación que pone en marcha entre el cuidar y su responsabilidad -que vive y siente, seguramente- desde una perspectiva políticopedagógica (Dussel y Southwell, 2005). Entonces, ¿por qué insistir en maneras supuestamente correctas de estar en el aula?, ¿cuál y hasta dónde nuestro compromiso y responsabilidad educativa es sólo pedagógica?

La crisis económica se nota en la escuela, nadie puede obviar lo que está pasando y aunque son criaturas pequeñas las situaciones que algunas viven en casa les genera inquietud, que expresan de distintas formas. ¿Cómo podemos proponerles actividades de aprendizaje desconociendo las experiencias que tienen en sus casas, en su contexto más próximo? Por ello, las formas de cuidado y atención deben acoger el interés, la prudencia desde el amor al otro para que la ansiedad y el desasosiego no irrumpan en la vida de estos niños (Dussel y Southwell, 2005), y se constituyan en obstaculizadores de y en sus aprendizajes. 
María comenta que "tradicionalmente los niños que asistían a esta escuela eran de clase mediaalta. Casi nunca, desde el Equipo Directivo o el Claustro nos habíamos planteado, por ejemplo, si por cuestiones económicas alguna actividad no se podía hacer. Desde hace unos años la cosa cambió. Hay familias que ya no pueden y se nota. La escuela y las maestras somos conscientes de ello e intentamos cuidar a estas criaturas y a través de ellas a sus familias. En la escuela hacemos una especie de campaña alentando a las familias a traer la ropa y zapatos que ya sus hijos o hijas no usan para repartirlos entre quienes lo necesitan, que no necesariamente son de la escuela. Por eso, cuando vemos a algún niño o niña que lo precisa, siempre hay cómo ayudar. A Nuria le encontramos unos zapatos que le iban de maravilla." (Extracto del diario de campo).

Acoger y cuidar tiene que ver también con nuestras biografías personales, que se entrelazan por la manera en que se interpreta la profesión. En el caso de María queda evidenciada esa vinculación cuando le adjudica un valor diferenciado a su experiencia pedagógica con estos niños y en la escuela, estimulando e intentando dar respuestas positivas a los requerimientos de quienes la rodean (Van Manen, 2014).

Algunas veces encontré a María mirando con ternura a Mireia, pues sigue su proceso con cautela y preocupación. Van Manen (1998) señala que "tocar a una persona puede ser más significativo que mil palabras" (p. 153). Parecería que esta afirmación la tiene muy clara la maestra con respecto a esta niña.

Es martes y son las 8.30 horas. Se acerca al aula un hombre joven llevando a una niña de la mano, es Mireia. María les sonríe y le pregunta a la niña cómo está, ya que el día anterior no había asistido a la escuela. Mireia no tiene tiempo a responder, es el hombre quien contesta exaltado: "Yo no puedo traer a Mireia (y sus hermanas) a la escuela. Vivo lejos". María le pregunta quién es él, a lo que responde: "Su padre, pero tranquila, no me verá más, ya que yo no me haré cargo de traer a las niñas a la escuela". El rostro de sorpresa de la maestra lo dice todo, el de dolor de la niña también. (Extracto del diario de campo).

Conocer y comprender lo que a una niña le está pasando implica escuchar y observar más allá de lo evidente y entender por qué Mireia busca un abrazo, la calidez de una mano, una mirada, que la impulsen, lo que según María implica "comprender la importancia de las cosas pequeñas" (Van Manen, 2014, p. 52), señales y síntomas que enmascarados de diferentes formas y modos se presentan y manifiestan en el aula. De allí que la tarea educativa de una maestra vaya más allá de lo curricular, intentando conciliar lo individual y lo grupal, lo particular y general, encontrando para cada niño el tiempo y el espacio para ser escuchado, asistido y acompañado en sus dificultades (Moreno, Villar y Blanco, 1998). Entraña, además, moderarse para no juzgar a un padre en un duro proceso de separación, que actúa de manera poco feliz delante de la niña que busca la mirada protectora de la maestra. Es ahí donde un docente con tacto, intuición y experiencia es capaz de ver la sensibilidad especial que reclama la situación, comprender el significado real de lo que está viendo y saber cómo y qué hacer, para hacer lo mejor por el bien de la niña (Van Manen, 1998).

Afirma Van Manen (2014, p. 16) que "los educadores con tacto han desarrollado la capacidad de mostrar una consideración afectuosa hacia lo singular: la singularidad de los niños, la singularidad de cada situación y de las vidas individuales". María, en más de una oportunidad, se convierte en mediadora entre las vivencias que estos niños tienen y las problemáticas y dificultades que desde el contexto próximo y más lejano les llegan e influyen. Su "solicitud pedagógica se asienta en una determinada forma de ver, escuchar y reaccionar ante un niño o unos niños determinados, en esta o aquella situación" (Van Manen, 2014, p. 17), intentando ver, escuchar y reaccionar de acuerdo a lo que las personas o situación le demandan.

Hace dos semanas que me extraña no ver a Mireia en el aula. Le pregunto a María si pasa algo y me cuenta: "Operaron de urgencia a la madre, y durante el tiempo que permanezca en reposo, Mireia y sus hermanas (de 4 y 5 años) no asistirán a la escuela porque están a cargo de sus abuelos, gente mayor, viven lejos de la escuela y no las puedan traer. Estoy muy preocupada ante esta situación, la madre hace lo que puede, no tiene prácticamente ayuda por parte del padre de las niñas. A la tercera semana llega la madre ya recuperada, se acerca a María y se funden en un sentido abrazo." (Extracto del diario de campo). 
Acompañar representa el desarrollo de una serie de capacidades transversales en los distintos ámbitos y momentos de la vida de una persona y no como una estrategia puntual, determinada y exclusiva a un tiempo y a un espacio específico (Comas y Funes, 2001). El abrazo entre la maestra y la madre encierra el gesto simbólico de la comprensión y acogimiento hacia una mujer sobrepasada por la situación, quien a pesar de todo está preocupada por el bienestar de su hija, ayudando a que en el largo proceso de separación de sus padres, Mireia vaya lo más ligera posible de equipaje (Duschatzky, 2014).

"Estimular y dar una respuesta positiva es uno de los gestos más comunes que se espera del profesor en el aula" (van Manen, 2014, p. 43). Casi todos esperan lo mismo, pero no todos comprenden ese gesto de la misma forma. De allí que esta manera de acoger y acompañar desde lo individual y singular de cada criatura, no está exenta de tensiones y resistencias principalmente con determinadas familias.

Cuando voy a la escuela observo que son siempre los mismos niños (2) y niñas (3) los que llegan tarde. María me comenta que ya no sabe cómo hacer para cambiar la situación. "Tendría que investigarse por qué pasa esto" -dice. El aula tiene dos puertas, una que da al patio y por la que entran todas las mañanas las criaturas y otra que da al pasillo interno de la escuela. Ha tomado la decisión, apoyada por el Equipo Directivo, de que los niños que lleguen tarde entrarán por la puerta interna. Esta medida ha generado cierto malestar en algunas familias que interpretan que "se les está castigando" con esa determinación. A pesar de esto, la situación no cambia sustancialmente. María me dice: "Рara mí, llegar a tiempo tiene una importancia vital, es el momento del primer encuentro del día, de que compartamos experiencias, vivencias, juguetes y también las tristezas, pero parece que desde fuera, algunas familias no lo ven. Creen que con criaturas de 3 años no se puede hacer mucho, que aquí solo vienen a jugar. P3 abre las puertas de la escolarización, es fundamental que tengan una buena experiencia porque a partir de ahora estarán mucho tiempo en la escuela. Pero algunas familias no lo ven." (Extracto del diario de campo).

Van Manen (2014, p. 15) sostiene que "la rutina no es sólo algo voluntario y familiar, sino que también puede ofrecer algo nuevo: la armonía y la melodía que alimentan el cuerpo y el alma". Esa es la armonía que desea cultivar María y que desde su sentir algunas familias no acompañan. Por ello es que gestionar los ruidos e interferencias que puedan existir entre la escuela y los progenitores resulta imprescindible, ya que acompañar no significa aceptar necesariamente todo y de cualquier manera. Van Manen (1998, p. 154) afirma que "el tacto describe lo que es adecuado hacer en una situación concreta. A veces, lo adecuado es ser directo, decidido y abierto en una situación en la que parece que eso es lo beneficioso", intentando, a través del diálogo, comprender lo que está pasando y por qué entre ambos términos de la relación: familia y escuela.

\subsection{Acoger con y desde la diferencia y las dificultades}

Acoger es también reconocer los conocimientos y saberes que las criaturas tienen, conocimientos que María va entretejiendo a partir de las experiencias que aportan, desde ellos, saberes que provienen de sus intereses, preocupaciones, de lo que les asusta y les gusta. Promover que esos saberes se socialicen, conceder al niño la posibilidad de posicionarse desde otro lugar, consigo mismo y en el grupo, es una manera de asistencia y pre-ocupación que alimenta la construcción de la personalidad que cada niño va elaborando, donde el elogio (van Manen, 2014) y la ponderación son formas de apoyo que contribuyen a la autoestima de los pequeños.

Desde que entré al aula de P3 advertí que Alberto tenía dificultades evidentes de aprendizaje, cuesta comprender lo que dice y su conducta resulta extraña hasta para sus pares. Sin embargo, es un experto en F1 y en moto GP. Cuando algún compañero trae un coche o moto de juguete, el niño explica con detalle las características de los mismos. María, con calma le va haciendo preguntas-guías para que pueda expresarse con claridad y explicar todo lo que sabe, que es mucho: "Alberto ¿cuántas ruedas tiene esta moto?, ¿y este coche?; ¿qué diferencias hay entre las ruedas de la moto y las del coche?", y Alberto responde con prontitud, a pesar de su dificultad es todo un experto. El resto de sus compañeros lo escuchan atentamente y le preguntan por qué los 
neumáticos son tan diferentes, por qué las motos tienen una forma u otra, etc." (Extracto del diario de campo).

Nuevamente, acoger a todos llena el aula: el abrazo entre la maestra y la madre, coches de F1 y motos GP, el dolor de pies de una niña, el malestar por la llegada tarde de algunas criaturas. Facilitar que el saber de un niño sea socializado es una manera de entender el encuentro pedagógico como un encuentro dialógico, donde ambos términos de la relación se implican, aportan y contribuyen en los aprendizajes de todos. Colocar el saber de Alberto en el centro de la relación posibilita a este niño verse de otra manera, desde la posibilidad y no desde la limitación. Y mientras sus pares aprenden a hacer un silencio respetuoso, a esperar y escuchar atentamente, así pueden preguntar lo que no saben.

Pero no todas las criaturas tienen la misma predisposición para la escucha y la espera. De allí que resulta necesario desarrollar una serie de habilidades sociales para poder integrase, relacionarse, cooperar y trabajar en equipo.

Me comenta María: “¿Sabes? Naiara es una niña muy inteligente, me llama la atención lo informada que está, siempre tiene respuestas a casi todas las preguntas, es madura. Pero me preocupa sobremanera a nivel social, no se relaciona con facilidad. Siempre quiere tener la razón y según con qué compañeros no quiere estar, ni siquiera en salidas informales de la escuela, icon Alberto ni hablar! Necesito trabajar con ella la empatía, el cuidado hacia sus compañeras y compañeros, estoy segura que podrá hacerlo, sólo debo ayudarla a conseguirlo." (Extracto del diario de campo).

María tiene un interés pedagógico por la vida de Naiara, "le une a ella una relación pedagógica, y no puede evitar verla como un ser humano único y completo en pleno proceso de crecimiento y formación personal (van Manen, 2014, p. 33). Por eso es que a sus capacidades intelectuales, la maestra las interprete como una posibilidad para trabajar lo que realmente le preocupa de esta niña: sus habilidades sociales. No obstante esta dificultad, María no categoriza a Naiara, no la constriñe en el lenguaje, ni la instrumentaliza (van Manen, 2014). La observa, la cuida y la pone en situación con amor y atención para que sea ella la que madure y aprenda a socializarse con sus pares.

Acoger y acompañar tiene que ver, asimismo, con reconocernos necesitados y dadores de cuidado, en una cadena de dependencias mutuas a pesar de la asimetría en la relación adultos y niños (Dussel y Caruso, 1999).

María faltó algunos días a la escuela y se nota. Las criaturas se acercan, la abrazan y besan y la maestra se deja abrazar y besar. En sus ojos vidriosos veo la emoción y amor que el reencuentro le produce. (Extracto del diario de campo).

María les dice a los niños cuánto las extrañó, se necesitan mutuamente. Los cuerpos pequeños de los niños se constituyeron en un instrumento de expresión de lo que ese encuentro representaba para todos, la alegría se hacía presente. Señala Maturana (1990, p. 5) que "desde el punto de vista biológico lo que connotamos cuando hablamos de emociones son disposiciones corporales dinámicas que definen los distintos dominios de acción en que nos movemos. Cuando uno cambia de emoción, cambia de dominio de acción". La emoción del encuentro se da, quizás, a partir de la vivencia de un espacio de convivencia donde el amor se evidencia, no está vetado:

El amor es la emoción que constituye las acciones de aceptar al otro como un legítimo otro en la convivencia; por lo tanto, amar es abrir un espacio de interacciones recurrentes con otro en el que su presencia es legítima sin exigencias. (Maturana, 1990, p. 31)

Es la hora del patio y estoy sentada en un banco. Se acerca una niña, se sienta junto a mí y comienza a llorar. Me acerco a ella y le pregunto qué le pasa y si la puedo ayudar. Es una niña que no conozco, no es de la clase de María. En ese momento es María la que se acerca y comienza a hablar con la niña (que sigue llorando), se sienta y la toma en brazos. Observo la naturalidad y 
familiaridad con la que la niña "se deja" abrazar, mientras María le acaricia la cabeza. Sentadas las tres en el banco, María comienza a contarme algunas anécdotas sobre cuestiones que la semana anterior habían pasado en la escuela. La niña en brazos, de a poco deja de llorar y se acurruca en el regazo de la maestra. En eso María la mira y con una sonrisa le pregunta si ya se siente bien. La niña asiente, la maestra le da un beso y como si de una señal se tratara, se baja y sale corriendo a jugar. (Extracto del diario de campo).

Solícita, la maestra actúa, exteriorizando un cuidado afectuoso hacia la situación y hacia la singularidad de la niña. No pregunta, sólo intenta dar respuesta a una circunstancia, aparentemente imprevista, pero que intuyo no es la primera vez que pasa. Van Manen (2014, p. 34) señala que "el profesor es un observador de niños [...] que contempla y tiene en cuenta la existencia total del niño que se está desarrollando" y en María se revela esa capacidad y manera de ser y hacer que le posibilita estar disponible y atenta a los signos o mensajes que las criaturas exteriorizan de distintas maneras, en un espacio donde los ruidos escenificados de diferentes modos- pueden confundirnos y hacernos dejar de ver lo que hay a nuestro alrededor. Esta forma de ver, escuchar y reaccionar de la maestra habla, quizás, de un tacto pedagógico que no conoce reglas (van Manen, 1998).

El poder que tiene el abrazo en la niña es curativo. No hicieron falta las palabras, el abrazo fue lo suficientemente significativo para que dejara de llorar. Esos brazos, ese contacto físico era lo que seguramente necesitaba para calmarse. Precisaba dejarse tocar. Y mientras los brazos protegen, dan seguridad y tranquilizan, el silencio de las palabras habla por sí solo en una conversación silenciosa y sutil donde el tacto serena y permite recobrarse a la niña.

\subsection{Aprendemos a vivir, a ser gradualmente autónomos}

Generar las condiciones para que el aprendizaje sea un proceso de producción crítica, posibilitando que la curiosidad se vivifique en sus alumnos, es algo que promueve María. "Curiosidad como inquietud indagadora, como inclinación a descubrir algo, como pregunta verbalizada o no, como búsqueda de esclarecimiento, como señal de atención que sugiere estar alerta" (Freire, 2008a, p. 33).

El aprendizaje a modo de espiral recurrente permite advertir el recorrido que cada niño va realizando. El tiempo pasaba y observaba cómo los niños se iban transformando en sujetos activos de y en la construcción y reconstrucción de saberes y conocimientos que desde la experiencia social tenían (Freire, 2008a), y que reelaboraban conjuntamente con María. Saberes a partir de los cuales la maestra hilvana los contenidos que el currículum señala, pero desde la libertad de decidir cuándo, cómo y qué enseñar a niños de 3 años. Lo importante para ella era crear las condiciones para que cada uno fuera logrando paulatinamente cierta independencia personal, adquiriendo libertad de movimiento.

María organiza actividades diferenciadas en el aula, o sea que no todos las criaturas hacen lo mismo a la vez. Mientras la mesa roja está con ella realizando alguna ejercitación puntual, los niños de la mesa verde dibujan en el pizarrón, los de la amarilla ven los libros y los de la azul están conmigo realizando otro trabajo. Concluida la tarea, cada uno sabe lo que debe hacer: guardar su producción en su lugar, dejar todo limpio y recogido para poder desayunar. (Extracto del diario de campo).

El logro de ciertos aprendizajes es factible si se es consciente de los obstáculos. Ello implica iniciar un camino de autoconocimiento y autoconciencia de las posibilidades y dificultades que, visualizadas, contribuye al cambio. Reconocer que cuesta hacer una actividad hace que el niño centre su atención y esfuerzo en ella, la perciba.

Estamos en el mes de enero y María me señala que los niños ya pueden ponerse solos las chaquetas para salir al patio. Zahida se acerca a la maestra y le pide que se la ponga. María le dice: "Zahida, yo te enseñaré, ya verás qué fácil resulta". Despacio le va explicando: "Primero pasa un brazo por esta manga, después el otro por la otra manga, te acomodas el cuello y ya estás lista para salir". Mientras María le indica, la niña sigue con la mirada atenta cada paso que debe hacer. 
Cuando regreso la semana siguiente, observo cómo la niña al colocarse la chaqueta, va ejecutando los movimientos con cuidado y conciencia, como recordando lo que María le había enseñado. Me mira sonriendo y levanta el pulgar como expresión de triunfo. (Extracto del diario de campo).

Contribuir gradualmente al logro de cierta independencia personal podría entenderse como la intención de ayudar a desarrollar en los niños la capacidad para hacer frente a los retos que desde la escuela se les plantea y que tienen que ver con una mirada hacia el futuro. Visto así, la independencia no se constituiría en un objetivo del trabajo educativo en sí mismo, sino en un principio regulador del proceso educativo; no como generadora de individualidades autosuficientes, sino como una independencia compatible con profundas vinculaciones afectivas y éticas, donde se reconoce y respeta la autonomía de los otros. Lograrla se constituiría en una competencia transversal, implícita en todo el proceso y en todas las áreas del desarrollo personal y educativo de las personas.

Para María que los niños tengan cierta autonomía personal significa que vayan tomando consciencia y pongan en marcha un conjunto de valores y actitudes personales interrelacionadas, como ser perseverantes, no rendirse ante la primera dificultad, enfrentar las obstáculos, aprender de los errores, aprender a pedir ayuda y suspender la necesidad de satisfacción inmediata de sus deseos. Este trabajo consciente de la maestra "no es sólo cognitivo en el sentido habitual. Es 'pático' (como en empático). Más que pensarse o razonarse, es un conocimiento que se siente." (van Manen, 2014, p. 59).

Partir de la premisa de que existen formas diferentes de vida, de familias y comunidades posibilita detenerse en la singularidad e individualidad, en los contextos específicos del otro (Suárez, 2011). Estar atento a los procesos individuales de los niños permite que cada uno reciba lo que en ese momento necesita, mayor atención o dejar que "vuele solo". Lo importante para María no es tanto si un niño va más rápido o más lento en sus aprendizajes, lo preocupante es cuando se detiene en el proceso.

\section{Conclusiones}

"Una trama policrómatica y peculiar" hace que los escenarios escolares posean una singularidad que los identifica. Por ello, las estrategias pedagógicas puestas en marcha deben estar "cargadas de significados muy específicos" (Suárez, 2011), donde la experiencia y el recorrido de la docente avalen su realización.

Compartir la investigación con María posibilitó volver la mirada a la práctica educativa desentrañando el saber, la experiencia y la ciencia en la que todo hacer pedagógico se fundamenta (Freire, 2008b). La práctica de la reflexión crítica fue una constante en María. Preguntarse, cuestionar, volver a reflexionar sobre su acciones, sobre lo que había sucedido o lo que dejó de hacer, la llevaba a descubrir los aciertos y desaciertos que cometía en el aula. Esta actitud crítica ante el proceso educativo le posibilitaba ampliar el horizonte del conocimiento científico, sin el cual superar errores hubiera sido difícil (Freire, 2008b).

El proceso de enseñanza-aprendizaje es un continuum en el que al avanzar o retroceder es necesario tener en cuenta al niño desde una biografía amplia. Esto hacía que las cosas que aparecían en el aula (a veces como simples anécdotas), María les adjudicaba "un sentido reflexivo, considerando la importancia pedagógica que pueden tener estas vivencias para los niños" (van Manen, 1998, p. 67). Por ello, la atención era una práctica pedagógica presente en el aula, y que requería agudizar la observación y distinguir los "signos", conductas, acciones que surgían en la cotidianidad y "mostraban" lo que le pasaba a un niño en concreto. Respetar las diferencias individuales y trabajar con cada uno a partir de ellas es posible en un clima escolar que favorece las condiciones de crecimiento personal de cada criatura. Es en un clima de confianza y aceptación al otro donde resulta fácil explicar que la noche anterior ya no se durmió en cama de los padres y se convierta en una gran noticia (para la familia) para ser compartida entre todos. Atender a los procesos individuales es reconocer las distintas capacidades intelectuales de los niños, pero también, y estrechamente vinculadas, las motivaciones personales y familiares, los estilos de aprendizajes, los contextos socio-familiares y económicos, los intereses, sentimientos y habilidades que poseen las criaturas. 
Escuchar y dialogar con las familias se constituye en un factor imprescindible para la gestión educativa. En el intercambio, en lo que le dicen y cómo lo hacen, María recibía información privilegiada que la ayudaba a trabajar desde la realidad de cada niño, logrando dar respuesta a lo que requería cada uno. Las cualidades pedagógicas que identifico en María tienen se entrelazan con la manera en que ella comprende, siente y vive la educación: como acontecimiento ético.

En la relación educativa, el rostro del otro irrumpe más allá de todo contrato y toda reciprocidad [...] La relación con el otro no es una relación contractual o negociada, no es una relación de dominación ni de poder, sino de acogimiento. Es una relación ética basada en una nueva idea de responsabilidad. (Bárcena y Mélich, 2000, p. 15).

Responsabilidad no exenta de tensiones y conflictos que a veces tiñen las relaciones entre los distintos colectivos representados en la escuela.

La reflexión recordatoria sobre la acción puede [...] hacerse mediante la conversación con otras personas. De hecho, suele ser conversando con otra persona como mejor podemos reflexionar sobre el significado de una situación en particular [...] Este contar y volver a contar anécdotas se puede ver como una forma de teorización práctica. (Van Manen, 1998, p. 128).

Fue justamente una reflexión recordatoria lo que guió el proceso investigativo, donde María pudo comprender y descubrir la importancia que su experiencia, alimentada cada día, tenía para poder relacionarse pedagógicamente con estos niños. Sin embargo, este proceso fue largo y hasta doloroso. En nuestras reflexiones-conversaciones habituales, María recordaba:

No te imaginas lo cuadrada que era, me costaba mucho salir del guión, era rígida, obstinada. Pero fue un acontecimiento familiar fuerte, inesperado, el que me hizo cambiar. Empecé a autorizarme, a darme cuenta que no pasaba nada si cambiaba algo, que podía innovar, transformar, inventar. Y esa experiencia personal es la que me guía con los niños y niñas, quiero que se animen, que si se equivocan no pasa nada, pero que lo intenten. (Extracto del diario de campo).

Experiencia personal que dejó su huella y que le permite que la curiosidad y la capacidad de sorprenderse - de lo bueno y de lo malo- frente a lo que le pasaba con los niños, las familias, sus pares, etc., la siga conmoviendo: emocionarse ante el abrazo afectuoso de unos hermanos en la hora del patio; preocuparse por una madre que está enferma y su niña que no puede venir a la escuela; mirar más allá del deseo de no caminar de Núria, habla de una maestra que desde una experiencia personal inicialmente rígida e inflexible, fue capaz de reinventarse, reflexionando conscientemente sobre los acontecimientos que iba viviendo.

Ser maestra de Infantil 3 no es tarea fácil. Estamos ante criaturas que por primera vez tienen contacto con la escuela, en la que permanecerán durante mucho tiempo. Los relatos de María permiten descubrir los sentidos de las propuestas metodológicas que realiza, donde lo importante es que "el niño se valore a sí mismo". Este es un aspecto que lo trabaja casi constantemente, al alentarlos y reconocer lo que hicieron bien, pero también señalándoles cuando algo está mal hecho. Las historias que discurren en el aula hacen que, a veces, cambie a mitad de camino por algo que no estaba previsto para ese día; a dar tiempo a los niños y a vivenciar "que un fracaso en la escuela no es un fracaso en la vida". En sus propuestas pedagógicas queda evidenciado que la vida va más allá de ciertos contenidos conceptuales, hay algo que para María es fundamental: "Que sus niños sean felices".

\section{Referencias}

Arévalo, A. (2007). Fundamentos metodológicos de la investigación doctoral: el sentido de la enseñanza de la filosofía en la educación secundaria. Comunicación presentada en el Seminario Internacional de Investigación en Ciencias Sociales y Educación, Universidad del Bio- Bio, Chillán, Chile. 
Arnaus, R. (1998). Metodología para la formación básica o apostar por una pedagogía para sujetos visibles. Revista Diálogos, 14, 33-40.

Bárcena F. y Melich J. C. (2000). La educación como acontecimiento ético. Barcelona: Paidós.

Bateson, M. C. (2004). Como yo los veía. Margaret Mead y Gregory Bateson recordados por su hija. Barcelona: Gedisa.

Boud, D., Cohen, R. y Walker, D. (Eds.) (2011). El aprendizaje a partir de la experiencia. Madrid: Narcea.

Comas, M. y Funes, J. (2001). Educadores i educadors de carrer: de l'opció ideològica a l'opció tecnicometodològica. Barcelona: Fundació Jaume Bofill.

Contreras, J. y Pérez, N. (2010). La experiencia y la investigación educativa. En J. Contreras y N. Pérez, Investigar la experiencia educativa (pp. 21-86). Barcelona: Morata.

Duschatzky, L. (2014). De la capacitación al acompañamiento. Novedades Educativas, 280, 86-89.

Dussel, I. y Caruso, M. (1999). La invención del aula. Buenos Aires: Santillana.

Dussel, I. y Southwell, M. (2005). En busca de otras formas de cuidado. Buenos Aires: Ministerio de Educación, Ciencia y Tecnología de la Nación.

Eisner, E. (1998). El ojo ilustrado. Indagación cualitativa y mejora de la práctica educativa. Barcelona: Paidós.

Freire, P. (2008a). Pedagogía de la autonomía. Buenos Aires: Siglo XXI.

Freire, P. (2008b). Cartas a quien pretende enseñar. Buenos Aires: Siglo XXI.

Garay, L. (1997). Conocer las instituciones. Algunas ideas para el diagnóstico (documento no publicado). Córdoba, Argentina.

Garay, L. (2000) Cuaderno de Postgrado: Algunos conceptos para analizar instituciones educativas. Córdoba, Argentina: Ferreyra Ed.

Godall, T. (2014). Vida cotidiana y transformaciones silenciosas. Revista Aula de infantil, 76, 11-16

Guber, R. (2012). La etnografía. Buenos Aires: Siglo XXI.

Hammersley, M. y Atkinson, P. (1994). Etnografía: métodos de investigación. Barcelona: Paidós.

Larrosa, J. (2009). Experiencia y alteridad en educación. En C. Skliar y J. Larrosa (Comps.), Experiencia y alteridad en educación (pp. 13-44). Argentina:Homo Sapiens.

Malinowski, B. (2007). Introducción: objeto, método y finalidad de esta investigación. En H. Velasco, F. J. García y A. Días (Eds.), Lecturas de antropología para educadores (pp. 21-42). Madrid: Trotta.

Marcelo, C. (2009). Formalidad e informalidad en el proceso de aprender a enseñar. Revista de Educación, $340,31-55$.

Maturana, H. (1990). Emociones y lenguaje en educación y política. España: Dolmen.

Milstein, D. y Mendes, H. (1999). La escuela en el cuerpo. Madrid: Miño y Dávila. 
Moreno, O., Villar, M. y Blanco, M. J. (1998). La experiencia de la tutoría como relación educativa en un Centro Residencial de Acción Educativa para adolescentes. Educación Social, 10, 70-81.

Mortari, L. (2002). Tras las huellas de un saber. En T. Escudero y A. D. Correa (Coords.), Diotima, el perfume de la maestra. En los laboratorios de la vida cotidiana (pp. 153-162). Barcelona: Icaria.

Orozco, S. (2014, septiembre). La práctica educativa de una maestra. Claves pedagógicas que guían su acción. Documento presentado en la European Conference on Educational Research (ECER), Oporto, Portugal.

Orozco, S. (2013, julio). Hilvanando saberes desde la relación pensante con la experiencia de una maestra. Documento presentado en el III Congreso Internacional de Etnografía y Educación. Madrid.

Reggio, P. (2010). El cuarto saber. Guía para el aprendizaje experiencial. España: Edicions del CREC.

Stake, R. (1998). Investigación con estudio de casos. Madrid: Morata.

Suárez, D. (2011). El saber de la experiencia. Maestros, narrativas y nuevas perspectivas para la formación docente continua. Universidad de Buenos Aires: CLACSO.

Van Manen, M. (1998). El tacto en la enseñanza: el significado de la sensibilidad pedagógica. Barcelona: Paidós.

Van Manen, M. (2003). Investigación educativa y experiencia vivida. Barcelona. Idea Books.

Van Manen, M. (2014). El tono en la enseñanza. El lenguaje de la pedagogía. Barcelona: Paidós.

Velasco, H., García, F. J. y Días, Á. (2007). Lecturas de antropología para educadores. Madrid: Trotta. 